\title{
Synergetic explosive performance through
}

\section{cocrystallization}

\author{
Christopher J. Snyder, ${ }^{\dagger}$ Gregory H. Imler, ${ }^{\ddagger}$ David E. Chavez ${ }^{\dagger}$ and \\ Damon A. Parrish \\ † Los Alamos National Laboratory, Los Alamos, NM, 87545, USA. \\ E-mail: csnyderelanl.gov \\ ‡ Naval Research Laboratory, Washington, DC 20375, USA
}

KEYWORDS: energetic materials, cocrystal

\section{Experimental}

CAUTION! The prepared compounds are highly energetic with sensitivity to various stimuli. Although we encountered no issues while working with these materials, proper protective measures (face shield, ear protection, body armor, Kevlar gloves and grounded equipment) should still be used at all times. 
General Methods: The ${ }^{1} \mathrm{H}$ and ${ }^{13} \mathrm{C}\left\{{ }^{1} \mathrm{H}\right\}$ NMR spectra were recorded at ambient temperature using a Bruker Ascend $400 \mathrm{MHz}$ spectrometer. Chemical shifts $(\delta)$ were referenced to the residual solvent signal. FTIR spectra were measured using a Thermo-Nicolet is5 FTIR spectrophotometer using OMNIC software. Elemental analyses were performed using a PerkinElmer series II 2400 CHNS/O analyzer. All reagents and solvents were used as received (Milipore-Sigma, Fluka, and Acros Organics). $\mathrm{H}_{2} \mathrm{DFP}$ was prepared according to literature procedures. ${ }^{1}$ CCDC 2030976 contains the supplementary crystallographic data for this paper. These data are provided free of charge by The Cambridge Crystallographic Data Centre.

Synthesis of cocrystal 1 .

In a 50-mL round-bottom flask equipped with a stir bar, $\mathrm{H}_{2} \mathrm{DFP}$ (1.00 9, $6.02 \mathrm{mmol})$ was dissolved in ethanol (20 mL). While stirring, a 50 \% solution of hydroxylamine $0.8 \mathrm{~mL}, 13.1 \mathrm{mmol}$ ) was added dropwise and a white precipitate began to form. The reaction was slowly heated to $50{ }^{\circ} \mathrm{C}$ to ensure complete dissolution of the materials. Stirring ceased and the reaction mixture was slowly cooled overnight resulting in $\mathrm{X}$-ray quality crystals of 1 (1.14 g, 82 으. $\mathrm{m} \cdot \mathrm{p}$. N/A; decomposition point $54{ }^{\circ} \mathrm{C} ;{ }^{1} \mathrm{H}$ NMR $\left(\mathrm{CD}_{3} \mathrm{CN}\right) \delta$ (ppm) $=3.21(\mathrm{br}, 8 \mathrm{H}) ;{ }^{13} \mathrm{C}\left\{{ }^{1} \mathrm{H}\right\} \quad\left(\mathrm{CD}_{3} \mathrm{CN}\right) \delta=147.6 ;$ Elemental analysis calc'd: C, 20.69; H, 3.47; N, 48.27; Found: C, 20.92; H, 3.86; N, 48.37 . 
Single-crystal X-ray Diffraction Analysis of cocrystal 1.

$\mathrm{C}_{4} \mathrm{H}_{8} \mathrm{~N}_{8} \mathrm{O}_{4}, \mathrm{FW}=232.18$, monoclinic, $\mathrm{P} 22_{1} / \mathrm{c}, \mathrm{a}=3.5405(3) \AA, \mathrm{b}=8.7479(8) \AA, \mathrm{c}=$ 13.3746(12) $\AA, \alpha=90^{\circ}, \beta=92.347(3)^{\circ}, \gamma=90^{\circ}, \mathrm{V}=413.89(6) \AA^{3}, \mathrm{Z}=2, \rho_{\text {calc }}(150 \mathrm{~K})=$ $1.863 \mathrm{Mg} / \mathrm{m}^{3}, \rho_{\text {calc }}(293 \mathrm{~K})=1.831 \mathrm{Mg} / \mathrm{m}^{3} \mu=0.163 \mathrm{~mm}^{-1}, F(000)=240, \mathrm{R}_{1}=0.0365$ for 930 observed $(\mathrm{I}>2 \sigma \mathrm{I})$ reflections and 0.0508 for all 1160 reflections, Goodness-of-fit $=1.076,78$ parameters.

A clear colorless needle crystal of dimensions $0.170 \times 0.077 \times 0.010 \mathrm{~mm}^{2}$ was mounted on a MiteGen MicroMesh using a small amount of Cargille Immersion Oil. Data were collected on a Bruker three-circle platform diffractometer equipped with a SMART APEX II CCD detector. The crystals were irradiated using graphite monochromated $\mathrm{MoK}_{\alpha}$ radiation $(\lambda=0.71073)$. An Oxford Cobra low temperature device was used to keep the crystals at a constant $150(2) \mathrm{K}$ during data collection.

Data collection was performed and the unit cell was initially refined using APEX3 [v2015.5-2]. ${ }^{2}$ Data Reduction was performed using SAINT [v8.34A] ${ }^{3}$ and XPREP [v2014/2] ${ }^{4}$. Corrections were applied for Lorentz, polarization, and absorption effects using SADABS [v2014/2]..$^{5}$ The structure was solved and refined with the aid of the program SHELXL-2014/7. ${ }^{6}$ The full-matrix least-squares refinement on $\mathrm{F}^{2}$ included atomic coordinates and anisotropic thermal parameters for all non- $\mathrm{H}$ atoms. The $\mathrm{H}$ atoms were included using a riding model except for $\mathrm{H} 4$ for which the coordinates were allowed to refine freely.

\section{Acknowledgements}

We would like to thank Lisa Kay, Hongzhao Tian, and Jose Archuleta for sensitivity testing, and thermal analysis and Ed Byrd for providing heat of formation and density calculations. The authors also thank the Office of Naval Research (Award No. N00014-11-AF-0-0002). 


\section{References}

(1) Tselinskii, I. V.; Mel'nikova, S. F.; Romanova, T. V.; Pirogov, S. V.; Khisamutdinov, G. K.; Mratkhuzina, T. A.; Korolev, V. L.; Kondyukov, I. Z.; Abdrakhmanov, I. S.; Smirnov, S. P. Russ. J. Org. Chem. 1997, 33, 1656-1665.

(2) Bruker (2015). APEX3 v2015.5-2. Bruker AXS Inc., Madison, Wisconsin, USA.

(3) Bruker (2013). SAINT v8.34A. Bruker AXS Inc., Madison, Wisconsin, USA.

(4) Bruker (2014). XPREP v2014/2. Bruker AXS Inc., Madison, Wisconsin, USA.

(5) Bruker (2014). SADABS v2014/5, Bruker AXS Inc., Madison, Wisconsin, USA.

(6) Sheldrick, G. M. (2014). SHELXL-2014/7. University of Göttingen, Germany. 